\title{
Pediatric inflammatory multisystem syndrome temporally associated with COVID-19: a spectrum of diseases with many names
}

\author{
Herman Tam MBBS MSc, Tala El Tal MD, Ellen Go MD, Rae S.M. Yeung MD PhD
}

- Cite as: CMAJ 2020 September 21;192:E1093-6. doi: 10.1503/cmaj.201600; early-released September 9, 2020

CMAJ Podcasts: author interview at https://www.cmaj.ca/lookup/doi/10.1503/cmaj.201600/tab-related-content

A 10-year-old previously healthy boy presented to the emergency department with 6 days of persistent fever; 4 days of abdominal pain, emesis and diarrhea; and bilateral nonpurulent conjunctivitis and red cracked lips. Four weeks before presentation, the patient had had 3 days of headache with no respiratory symptoms, and he and his family had tested positive for severe acute respiratory syndrome coronavirus 2 (SARS-CoV-2) on nasopharyngeal swab. On arrival at the emergency department, his blood pressure was $74 / 35 \mathrm{~mm} \mathrm{Hg}$ and heart rate was 130 beats/min despite $60 \mathrm{~mL} / \mathrm{kg}$ of fluid resuscitation. He was cool and had poor perfusion. He received inotrope support and empiric antibiotics and was transferred to the intensive care unit (ICU).

Laboratory results on admission (Table 1 ) were clinically significant for leukocytosis, neutrophilia, lymphopenia, thrombocytopenia, elevated C-reactive protein (CRP), hyperferritinemia, hyponatremia, hypoalbuminemia, hypertriglyceridemia, acute kidney injury, transaminitis, coagulopathy, and markedly elevated troponin and $\mathrm{N}$-terminal-pro-brain natriuretic peptide (NT-proBNP). Electrocardiography (ECG) showed conduction abnormality and an echocardiogram showed signs of myocarditis with no coronary artery changes or aneurysms. The patient's result for a nasopharyngeal swab for SARSCoV-2 was negative on polymerase chain reaction (PCR) testing, but the result for serology testing was positive. We diagnosed pediatric inflammatory multisystem syndrome characterized by features of Kawasaki disease, cardiogenic shock, myocarditis, liver dysfunction, acute kidney injury and evolving macrophage activation syndrome.

On admission to hospital, we provided the patient with concurrent treatment with intravenous pulse methylprednisolone ( $30 \mathrm{mg} / \mathrm{kg} / \mathrm{d}$ ) for 4 days, followed by a slow taper, and a dose of intravenous immunoglobulin (IVIG; $2 \mathrm{~g} / \mathrm{kg}$ ). Inotrope support was stopped by the fourth day after admission (DAA 4). Because of persistent fever and cytopenias, we added anakinra, a recombinant interleukin (IL)-1 receptor antagonist, at $100 \mathrm{mg} / \mathrm{d}$ (about $2.75 \mathrm{mg} / \mathrm{kg} / \mathrm{d}$ ) on DAA 7. His fever resolved on the same day. We started treatment with low-dose acetylsalicylic acid (antiplatelet dose of 3-5 mg/kg/d) when the patient's platelet count recovered by DAA 9 . His renal function and troponin levels returned to normal on DAA 3 and 8, respectively. On DAA 10, clinical and biochemical

\section{KEY POINTS}

- Pediatric inflammatory multisystem syndrome is an uncommon emerging hyperinflammatory disorder temporally associated with coronavirus disease 2019 (COVID-19); it has a wide spectrum of disease severity typified by 3 clinical phenotypes: shock, Kawasaki disease and fever and inflammation.

- Common clinical features include prolonged fever; classic features of Kawasaki disease; cardiac dysfunction; and gastrointestinal, neurologic and/or renal involvement.

- Laboratory profiles of hyperinflammation include significantly elevated C-reactive protein, lymphopenia, neutrophilia, thrombocytopenia, hyponatremia and hypoalbuminemia.

- Immunomodulatory treatments used in Kawasaki disease may be considered, including intravenous immunoglobulin or glucocorticoids.

improvement continued, and we discharged the patient, keeping him on anakinra and tapering his dose of prednisone. His length of stay in the ICU and in hospital was 5 and 10 days, respectively.

At follow-up, the patient remained clinically well with improving inflammatory markers. He developed thrombocytosis that peaked at $545 \times 10^{9} / \mathrm{L}$, which coincided with desquamation of his upper and lower extremities, as is seen in Kawasaki disease. Repeat ECG and echocardiogram were normal apart from small pericardial effusion. The patient was weaned off steroids after 3 weeks of treatment, and he remains on anakinra at the time of writing.

\section{Discussion}

\section{Epidemiology}

Global epidemiologic studies in the current coronavirus disease 2019 (COVID-19) pandemic indicate that children are less affected than adults. In Canada, those aged 19 years or younger account for $8.0 \%$ of all COVID-19 cases and $1.2 \%$ of cases admitted to hospital (as of Aug. 4, 2020, per Public Health Agency of Canada, available at https:// health-infobase.canada.ca/covid-19/epidemiological-summary -covid-19-cases.html). Compared with adults, most of the children 
Table 1: Laboratory investigations on admission to hospital

\begin{tabular}{|c|c|c|}
\hline Investigation & Result & $\begin{array}{l}\text { Reference } \\
\text { range }\end{array}$ \\
\hline White blood cell count, $\times 10^{9} / \mathrm{L}$ & 13.41 & $4.31-11.00$ \\
\hline Absolute neutrophil count, $\times 10^{9} / \mathrm{L}$ & 8.70 & $1.63-7.55$ \\
\hline Absolute lymphocyte count, $\times 10^{9} / \mathrm{L}$ & 0.36 & $>3$ \\
\hline Hemoglobin, g/dL & 101 & $107-134$ \\
\hline Platelets, $\times 10^{9} / \mathrm{L}$ & 30 & $206-369$ \\
\hline C-reactive protein, $\mathrm{mg} / \mathrm{L}$ & 268.9 & $0.1-1.0$ \\
\hline $\mathrm{ESR}, \mathrm{mm} / \mathrm{h}$ & 9 & $2-34$ \\
\hline Ferritin, $\mathrm{ng} / \mathrm{mL}$ & 1061.5 & $13.7-78.8$ \\
\hline Sodium, $\mathrm{mmol} / \mathrm{L}$ & 132 & $135-143$ \\
\hline Albumin, $g / d L$ & 22 & $37-50$ \\
\hline Alanine transaminase, $\mathrm{U} / \mathrm{L}$ & 81 & $<24$ \\
\hline Aspartate transaminase, $\mathrm{U} / \mathrm{L}$ & 84 & $<43$ \\
\hline Creatinine, $\mu \mathrm{mol} / \mathrm{L}$ & 182 & $25-50$ \\
\hline D-Dimer, $\mu \mathrm{g} / \mathrm{mL}$ & 3.35 & $<0.50$ \\
\hline Fibrinogen, g/L & 6.6 & $1.9-4.3$ \\
\hline International normalized ratio & 1.4 & $0.8-1.2$ \\
\hline Triglycerides, $\mathrm{mmol} / \mathrm{L}$ & 3.35 & $<1.02$ \\
\hline Troponin I, ng/L & 199.7 & $<30.9$ \\
\hline NT-proBNP, pmol/L & 2960 & $<150$ \\
\hline Nasopharyngeal SARS-CoV-2 PCR & Negative & NA \\
\hline Anti-SARS-CoV-2 IgG & Positive & NA \\
\hline ECG & $\begin{array}{l}\text { Sinus tachycardia } \\
\text { RV conduction } \\
\text { delay }\end{array}$ & NA \\
\hline Echocardiography & $\begin{array}{l}\text { Normal coronary } \\
\text { arteries, } \\
\text { moderately } \\
\text { reduced RV } \\
\text { function, echo } \\
\text { bright areas on LV } \\
\text { myocardium and } \\
\text { papillary muscles, } \\
\text { small pericardial } \\
\text { effusion }\end{array}$ & NA \\
\hline
\end{tabular}

Note: $E C G=$ electrocardiogram, ESR = erythrocyte sedimentation rate, IgG = immunoglobulin $\mathrm{G}, \mathrm{LV}=$ left ventricle, NA = not applicable, NT-proBNP = N-terminal-pro-brain-type natriuretic peptide, $\mathrm{PCR}=$ polymerase chain reaction, $\mathrm{RV}=$ right ventricle, $\mathrm{SARS}-\mathrm{CoV}-2$ = severe acute respiratory syndrome coronavirus 2.

with positive results for SARS-CoV-2 testing are asymptomatic or have mild disease during the acute infectious stage. In Toronto, cases of COVID-19 started to surge in late March to early April. Four weeks later, we observed an increasing number of children presenting with the newly described pediatric inflammatory multisystem syndrome.

\section{Case definitions}

On Apr. 7, 2020, the first case of Kawasaki disease with a positive result for SARS-CoV-2 on PCR was reported in a 6-month-old girl with fever, features of Kawasaki disease and minimal respiratory symptoms. ${ }^{1}$ On
Apr. 25, 2020, the United Kingdom National Health Service sent a public health alert to doctors advising of the emergence of an unusual disorder of multisystem inflammation in children with varying cardiac and gastrointestinal involvement, with features of Kawasaki disease and toxic shock syndrome. Since then, there has been an alarming increase in the number of cases along with several case definitions and names proposed, including pediatric inflammatory multisystem syndrome temporally associated with COVID- $19^{2}$ and multisystem inflammatory syndrome in children. ${ }^{3,4}$ Common elements to these definitions are the presence of prolonged fever, multiorgan dysfunction, laboratory evidence of hyperinflammation, with or without SARS-CoV-2 infection or exposure, and no alternative cause to explain the clinical presentation (Table 2)..$^{5}$ On May 12, 2020, the Canadian Paediatric Surveillance Program issued a public health alert to Canadian providers. ${ }^{6}$ Reports of this new postinfectious hyperinflammation syndrome have since been published from countries most affected by COVID-19, including the UK, Italy, France and USA. ${ }^{7-10}$

\section{Epidemiologic link to SARS-CoV-2}

Although pediatric inflammatory multisystem syndrome is epidemiologically related to COVID-19, interestingly, not all case definitions require evidence of SARS-CoV-2 infection or exposure. ${ }^{2}$ Most reported cases in other countries have identified positive serologic evidence of SARS-CoV-2 infection, with a small percentage of children having a positive result for the virus on nasopharyngeal swab PCR testing. Other exposure criteria include a preceding illness compatible with acute SARS-CoV-2 infection 4-6 weeks before, suspected or confirmed exposure or contact, and residing in areas with high COVID-19 caseloads. Serological testing is not yet available as a validated clinical assay in Canada, as national standards are being developed. As part of the diagnostic evaluation of suspected pediatric inflammatory multisystem syndrome, pretreatment serum samples should be saved for future analysis once clinical serology testing is available.

\section{Pathophysiology}

Blood vessels are thought to be the primary target of endothelial inflammation and injury triggered by SARS-CoV-2, ${ }^{11}$ mirroring the immunobiology identified in Kawasaki disease. Although the exact pathophysiology of pediatric inflammatory multisystem syndrome has yet to be determined, the presence of SARS-CoV-2 antibodies, specific T-cell response and delayed presentation after the peak of acute infections points to a potential role for acquired immunity such as enhancement of viral entry or a pro-inflammatory response mediated by antibodies or immune complexes. ${ }^{7,8}$ This possibility has important implications for vaccine development and is an area of active study.

In severe cases, a dysregulated immune response can result in overactive monocyte-derived macrophages with an increased production of cytokine and chemokines similar to that seen in macrophage activation syndrome..$^{5}$ Macrophage activation syndrome is a cytokine storm syndrome secondary to uncontrolled activation and proliferation of $\mathrm{T}$ cells and macrophages that is characterized by nonremitting fever, cytopenia, hyperferritinemia, liver dysfunction and coagulopathy. ${ }^{5}$ Patients are unwell with hemodynamic instability and multiorgan involvement, and their condition can deteriorate rapidly - a clinical scenario seen in children with pediatric inflammatory multisystem syndrome. 
Table 2: Comparison of case definitions for pediatric inflammatory multisystem syndrome ${ }^{5}$

Source of definition

\begin{tabular}{|c|c|c|c|c|}
\hline Feature & $\mathrm{RCPCH}^{2}$ & $\mathrm{CDC}^{3}$ & WHO 4 & CPSP $^{5}$ \\
\hline Name of syndrome & $\begin{array}{l}\text { Pediatric multisystem } \\
\text { inflammatory syndrome } \\
\text { temporally associated } \\
\text { with COVID-19 (PIMS-TS) }\end{array}$ & $\begin{array}{l}\text { Multisystem } \\
\text { inflammatory syndrome } \\
\text { in children (MIS-C) }\end{array}$ & $\begin{array}{l}\text { Multisystem inflammatory } \\
\text { syndrome in children } \\
\text { (MIS-C) }\end{array}$ & $\begin{array}{l}\text { Pediatric inflammatory } \\
\text { multisystem syndrome temporally } \\
\text { associated with COVID-19 (PIMS) }\end{array}$ \\
\hline Fever & Persistent at $>38.5^{\circ} \mathrm{C}$ & $\begin{array}{l}>38.0^{\circ} \mathrm{C} \text { OR subjective } \geq \\
24 \mathrm{~h}\end{array}$ & $\geq 3 \mathrm{~d}$ & $>38.0^{\circ} \mathrm{C}$ for $\geq 3 \mathrm{~d}$ \\
\hline Age & $\begin{array}{l}\text { Not specified } \\
\text { "child" }\end{array}$ & $<21 \mathrm{yr}$ & $0-19 \mathrm{yr}$ & $<18 \mathrm{yr}$ \\
\hline Multisystem & $\begin{array}{l}\text { Single organ or } \\
\text { multiorgan dysfunction } \\
\text { AND } \\
\text { additional features* }^{\star}\end{array}$ & $\geq 2$ organ systems $\dagger$ & $\geq 2$ features $\ddagger$ & Not specified but implied§ \\
\hline Laboratory features & $\begin{array}{l}\text { Neutrophilia, } \\
\text { lymphopenia and } \\
\text { elevated CRP }\end{array}$ & $\begin{array}{l}\text { One or more of the } \\
\text { following: elevated CRP, } \\
\text { ESR, fibrinogen, } \\
\text { procalcitonin, D-dimer, } \\
\text { ferritin, LDH or IL-6; } \\
\text { neutrophilia, lymphopenia, } \\
\text { low albumin }\end{array}$ & $\begin{array}{l}\text { Elevated ESR, CRP or } \\
\text { procalcitonin }\end{array}$ & Elevated CRP, ESR or ferritin \\
\hline Excludes other causes & No & No & Yes & No \\
\hline $\begin{array}{l}\text { SARS-CoV-2 PCR, } \\
\text { antibodies or } \\
\text { exposure necessary }\end{array}$ & No & Yes & Yes & No \\
\hline
\end{tabular}

Note: $\mathrm{CDC}=$ Centers for Disease Control and Prevention, COVID-19 = coronavirus disease 2019, CPSP = Canadian Paediatric Surveillance Program, CRP = C-reactive protein, ESR = erythrocyte sedimentation rate, IL-6 = interleukin 6, LDH = lactate dehydrogenase, NT-proBNP = N-terminal-pro-brain natriuretic peptide, RCPCH = Royal College of Paediatrics and Child Health, SARS-CoV-2-PCR = severe acute respiratory syndrome coronavirus 2 polymerase chain reaction, WHO = World Health Organization. Source: Adapted from Berard RA, Scuccimarri R, Haddad EM, et al. Paediatric inflammatory multisystem syndrome temporally associated with COVID-19: www.cps.ca/en/documents/position/pims. ${ }^{5}$

*Shock, cardiac, respiratory, renal, gastrointestinal or neurologic disorder. This may include children with full or partial criteria for Kawasaki disease.

tCardiac, renal, respiratory, hematologic, gastrointestinal, dermatologic or neurologic systems.

$\ddagger$ Admission to hospital and 2 of the following: rash, bilateral nonpurulent conjunctivitis, mucocutaneous inflammation signs (oral, hands or feet); hypotension or shock; cardiac involvement: features of myocardial dysfunction, pericarditis, valvulitis or coronary abnormalities (including echocardiography findings or elevated troponin/NT-proBNP); evidence of coagulopathy (by prothrombin time, partial thromboplastin time, elevated D-dimers); acute gastrointestinal problems (diarrhea, vomiting or abdominal pain).

$\S A d m i s s i o n$ to hospital and features of Kawasaki disease (complete or incomplete) or toxic shock syndrome (typical or atypical).

\section{Disease spectrum of pediatric inflammatory multisystem syndrome}

Like Kawasaki disease, pediatric inflammatory multisystem syndrome is a syndrome complex with a wide spectrum of clinical phenotypes. Both entities are infection-triggered hyperinflammatory syndromes with varying degrees of complications such as cardiogenic shock and macrophage activation syndrome at the severe end of the spectrum, and a self-limited febrile illness at the mild end. Three clinical patterns have emerged in pediatric inflammatory multisystem syndrome: shock, Kawasaki disease, and fever and inflammation.

The pediatric inflammatory multisystem syndrome-shock phenotype has several clinical features overlapping with toxic shock syndrome and Kawasaki disease shock syndrome. Children are critically ill and hypotensive, with a high degree of hyperinflammation (significantly elevated CRP, hyperferritinemia, neutrophilia, lymphopenia), substantially elevated cardiac markers (troponin and NT-proBNP), hypoalbuminemia, hyponatraemia and ECG abnormalities..$^{7-10}$ A stepwise approach to expand investigations for children with suspected pediatric inflammatory multisystem syndrome should include the bloodwork listed previously, which can aid in the identification of children at high risk for developing cardiogenic shock and to guide management. Fluid resuscitation should be used cautiously, as fluid overload may develop in those with cardiogenic shock. Intensive care support including mechanical ventilation and inotropes may be required.

The pediatric inflammatory multisystem syndrome-Kawasaki disease phenotype shares many similarities with Kawasaki disease that are unrelated to SARS-CoV-2 infection. Shared features include fever $\left(38.5^{\circ} \mathrm{C}\right) 5$ days or longer plus the classic diagnostic features of Kawasaki disease (i.e., rash, nonexudative conjunctival injection, oromucosal changes [strawberry tongue, red and/or cracked lips], peripheral changes [swelling and/or redness of the hands and feet] and cervical lymphadenopathy, and the consequences of vascular inflammation leading to damage to the coronary arteries and aneurysm formation). ${ }^{12}$ Some differences have been noted in pediatric inflammatory multisystem syndrome, including older age; higher prevalence among patients of Afro-Caribbean descent; prominent gastrointestinal, neurologic and renal symptoms; severe cardiac morbidity such as myocarditis and ventricular dysfunction; and higher frequency of shock and macrophage activation syndrome. ${ }^{7-10}$ 
The pediatric inflammatory multisystem syndrome-fever and inflammation phenotype is the mildest. These children present with fever and biochemical evidence of hyperinflammation but no clinical features of Kawasaki disease or shock. Patients seen at our centre commonly developed marked thrombocytosis at follow-up, a feature consistent with the subacute phase of Kawasaki disease. ${ }^{12}$ Coronary artery aneurysms and myocardial injury can occur in all 3 phenotypes even in the absence of the features of Kawasaki disease. Fortunately, some case series have reported self-resolution of coronary artery aneurysms without acute treatment; however, long-term follow-up is needed to determine the appropriate action in patients who did not have aneurysms at initial screening.

\section{Investigations and management}

In July 2020, the American College of Rheumatology (ACR) ${ }^{13}$ and Canadian Paediatric Society (CPS) ${ }^{5}$ issued clinical guidance for the investigation and management of suspected pediatric inflammatory multisystem syndrome in children. A child with suspected pediatric inflammatory multisystem syndrome should also be evaluated for other infectious and noninfectious causes. The prevalence of SARS-CoV-2 in a given location should be considered because pediatric inflammatory multisystem syndrome is temporally associated with infection or exposure. Given the lack of data to guide decisions, most guidance has erred on the side of caution and cast a wide net to identify children at risk. The CPS has proposed screening investigations for children with unexplained fevers for more than 3 days in whom other causes have been excluded. ${ }^{5}$ Clinical guidance will be evaluated regularly, as more data become available, to adjust decision parameters capable of capturing cases while avoiding unnecessary investigations and take into account the availability of local resources.

There are no direct comparisons of therapeutic approaches to date. Most management pathways have adapted the use of immunomodulatory agents, including IVIG and steroids, thromboprophylaxis and protocols for cardiac surveillance imaging for Kawasaki disease, given their similarities. Use of biologic agents, such as anti-IL-1, are to be considered in patients refractory to IVIG or steroids. ${ }^{5,13}$ Treatment response and tapering of immunosuppressive agents should be guided by serial clinical, laboratory and cardiac assessments.

\section{Future directions}

A rigorous scientific approach to data collection and analysis using internationally harmonized definitions is needed to improve our understanding of this emerging syndrome and to help guide clinical decision-making. The CPS, in collaboration with the Public Health Agency of Canada, has expanded its active surveillance in COVID-19 to include cases of pediatric inflammatory multisystem syndrome or Kawasaki disease at a national level. ${ }^{6}$ Canada is in an enviable position to benefit from the lessons learned from countries that experienced the COVID-19 pandemic earlier, giving us the ability to raise awareness for pediatric inflammatory multisystem syndrome, and to develop and implement management pathways for suspected cases. ${ }^{5}$

\section{References}

1. Jones VG, Mills M, Suarez D, et al. COVID-19 and Kawasaki disease: novel virus and novel case. Hosp Pediatr 2020;10:537-40.

2. Guidance: paediatric multisystem inflammatory syndrome temporally associated with COVID-19. London (UK): Royal College of Paediatrics and Child Health; 2020. Available: www.rcpch.ac.uk/resources/guidance-paediatric-multisysteminflammatory-syndrome-temporally-associated-covid-19 (accessed 2020 June 10).

3. Multisystem inflammatory syndrome in children (MIS-C) associated with coronavirus disease 2019 (COVID-19). Atlanta: Centers for Disease Control and Prevention; 2020 May 14. Available: https://emergency.cdc.gov/han/2020/ han00432.asp (accessed 2020 June 10).

4. Multisystem inflammatory syndrome in children and adolescents with COVID19. Geneva: World Health Organization; 2020 May 15. Available: www.who. int/publications-detail/multisystem-inflammatory-syndrome-in-children-and -adolescents-with-covid-19 (accessed 2020 June 10).

5. Berard RA, Scuccimarri R, Haddad EM, et al. Paediatric inflammatory multisystem syndrome temporally associated with COVID-19. Ottawa: Canadian Paediatric Society; 2020July 6. Available: www.cps.ca/en/documents/position/pims (accessed 2020 Aug. 4).

6. Public health alert: acute inflammatory illness in children temporarily linked to COVID-19. Ottawa: Canadian Paediatric Surveillance Program; 2020 May 14. Available: www.cpsp.cps.ca/uploads/private/CPSP_Public_Health_Alert_ Acute_inflammatory_illness_and_COVID-19.pdf (accessed 2020 June 10).

7. Whittaker E, Bamford A, Kenny J, et al. Clinical characteristics of 58 children with a pediatric inflammatory multisystem syndrome temporally associated with SARS-CoV-2. JAMA 2020; 324:259-69.

8. Verdoni L, Mazza A, Gervasoni A, et al. An outbreak of severe Kawasaki-like disease at the Italian epicentre of the SARS-CoV-2 epidemic: an observational cohort study. Lancet 2020;395:1771-8.

9. Belhadjer Z, Méot M, Bajolle F, et al. Acute heart failure in multisystem inflammatory syndrome in children (MIS-C) in the context of global SARS-CoV-2 pandemic. Circulation 2020;142:429-36.

10. Feldstein LR, Rose EB, Horwitz SM, et al. Multisystem inflammatory syndrome in U.S. children and adolescents. N Engl J Med 2020;383:334-46.

11. Varga Z, Flammer AJ, Steiger $P$, et al. Endothelial cell infection and endotheliitis in COVID-19. Lancet 2020;395:1417-8.

12. McCrindle BW, Rowley AH, Newburger JW, et al.; American Heart Association Rheumatic Fever, Endocarditis, and Kawasaki Disease Committee of the Council on Cardiovascular Disease in the Young; Council on Cardiovascular and Stroke Nursing; Council on Cardiovascular Surgery and Anesthesia; and Council on Epidemiology and Prevention. Diagnosis, treatment, and long-term management of Kawasaki disease: a scientific statement for health professionals from the American Heart Association. Circulation 2017;135:e927-99.

13. Wahezi DM, Lo MS, Rubinstein TB, et al. American College of Rheumatology guidance for the management of children with pediatric rheumatic disease during the COVID-19 pandemic: version 1. Arthritis Rheumatol 2020 July 23 [Epub ahead of print];10.1002/art.41455. doi: 10.1002/art.41455.

\section{Competing interests: None declared.}

This article has been peer reviewed.

The authors have obtained parental consent.

Affiliation: Division of Rheumatology, The Hospital for Sick Children, Toronto, Ont.

Contributors: Rae Yeung contributed to the conception and design of the work. All of the authors acquired, analyzed and interpreted the data; drafted and critically revised the manuscript for important intellectual content; gave final approval of the version to be published; and agreed to be accountable for all aspects of the submitted manuscript.

Funding: Rae Yeung is supported by the Hak-Ming and Deborah Chiu Chair in Paediatric Translational Research at the Hospital for Sick Children, University of Toronto, Toronto, Ont.

Correspondence to: Rae Yeung, rae.yeung@sickkids.ca 